Administrative Issues Journal: Connecting Education, Practice, and Research, Summer 2020,

Vol. 10, No. 1: 30 - 45. DOI: 10.5929/2020.10.1.3

\title{
Gender Difference in STEM Career Aspiration and Social- Cognitive Factors in Collectivist and Individualist Cultures
}

\author{
Wei-Cheng Mau. Ph.D. \\ Wichita State University \\ Shr-Jya Chen, Ph.D. \\ Tunghai University \\ Jiaqi Li, Ph.D., LPC, NCC \\ Wichita State University \\ Emily Johnson, Graduate Student \\ Wichita State University
}

\begin{abstract}
Gender equity in STEM demands that girls and women are provided with learning experiences, opportunities, and resources that meet their educational and vocational goals. This study examined gender difference in STEM learning experience, parental involvement, and self-efficacy to predict STEM career aspiration of different sociocultural groups. Two independent samples of high school students, one recruited from a collectivist culture (Taiwanese sample, $N=590$ ) and the other recruited randomly from an individualist culture (American sample, $N=590$ ), were used to examine the differences. Findings suggested a greater gender difference in STEM learning experience, parental involvement, and STEM self-efficacy of students from the collectivist culture than students from the individualist culture. Results of logistic analyses showed differential prediction of STEM career aspiration in two different cultural contexts. Findings were discussed in light of socio-cultural contexts.
\end{abstract}

Keywords: gender difference, stem career aspiration, social-cognitive career theory, individualism and collectivism, high school student

\footnotetext{
G
}

ender equity in education and career development has been a social and political issue for policymakers, educators, and researchers around the world. Concerns about the gender gap in science, technology, engineering and mathematics (STEM) participation and inadequate preparation of female high school students are pervasive and drawing considerable research attention (Ing, 2014; Kanny et al., 2014; Li et al., 2019; Mau et al., 2019; Mau et al., 1995; Mau \& Li, 2018; Wang \& Degol, 2013). Despite extensive research and policy efforts, gender disparity in STEM participation in educational and vocational fields has remained consistent in many countries (Ganley et al., 2018; 
Gender Difference in STEM Career Aspiration and Social-Cognitive Factors in Collectivist and Individualist Cultures

Thurlings et al., 2014; United Nations Educational, Scientific and Cultural Organization [UNESCO], 2017; Wang \& Degol, 2013).

There are a number of factors that have been identified as hindrances to gender equity in STEM fields. For example, disparities in career related self-efficacy (Brown, et al., 2016; Mau, 2000; Usher et al., 2019), exposure to STEM career fields (Brotman \& Moore, 2008; Lent, Brown, \& Hackett, 2000), gender-related stereotypes and biases (Mau, Domnick, \& Ellsworth, 1997; Wang, 2012), influence of teachers, parents and peers (Christensen, Knezek, \& Tyler-Wood, 2015; Mau \& Li, 2018). However, not enough attention has been paid to the sociocultural factor impacting STEM field gender disparity. Researchers need to look beyond STEM literature for answers to explain gender difference across countries with diverse sociocultural contexts. Better understanding of the impact that the different sociocultural contexts has on students' STEM participation can help inform more nuanced approaches by school guidance counselors. Based on Social Cognitive Career Theory (SCCT; Lent et al., 1994) and a synthesis of the literature regarding career aspiration (Mau, 2003; Mau \& Bikos, 2000; Mau \& Li, 2018), we examined gender difference from two culturally different samples (i.e., United States and Taiwanese high school students) to understand this complex phenomenon.

\section{Theoretical Framework}

SCCT has been widely used as a theoretical framework to explain learning experience and career aspiration. Derived from Bandura's (1977) social cognitive theory, (SCT; Lent et al., 1994) posits that career development is influenced by continuous interactions between individual factors (e.g., race and gender), contextual factors (e.g., parental support and learning experience), and personal cognitive factors (e.g., self-efficacy). The core of the SCCT consists of cognitive-personal variables: learning experiences, self-efficacy, outcome expectations, interests, and goals. In SCCT, self-efficacy and outcome expectations largely mediates the effect of learning experiences on career interests, choice goals, and choice actions. Roberts et al. (2018) found that STEM learning experiences increase students' aspiration in STEM and their chances of pursuing a STEM career.

\section{STEM Self-Efficacy}

In SCCT, self-efficacy belief is an organizing mechanism that influences individuals' decisions to engage in a goal-oriented task (Lent et al., 1994, 2000). One's background and STEM learning experiences shape the development of self-efficacy and career aspiration, which in turn influence one's educational and vocational choices in STEM fields (Wang \& Degol, 2013). Empirical studies have shown that subject-specific (e.g., math) career self-efficacy affects STEM career aspiration (Mau, 2003; Mau et al., 2019; Raque-Bogdan \& Lucas, 2016). For example, Mau (2003) found mathematics self-efficacy predicted eight grade students' persistence in aspiring to a science or engineering career. Similarly, Fouad and Smith (1996) found that mathematics and science self-efficacy was associated with careerrelated goals and intentions of minority and low-income students.

\section{Parental Involvement}

There has been extensive discussion of the important role of parental involvement in children's educational and career success (Ing, 2014; Jeynes, 2003; Mau \& Biko, 2000; Mau \& Li, 2018; Sy et al., 2007). Based on a systematic review of 324 peer-reviewed texts over a 40-year period, Kanny et al. (2014) identified that structural barriers in K-12 education and family influence encompass two of the five dominant factors that have explained the gender difference in college STEM majors. Wang (2012) suggested that parents who support their children in developing interests in mathematics and science 
Gender Difference in STEM Career Aspiration and Social-Cognitive Factors in Collectivist and Individualist Cultures

are more likely to cause their children to eventually pursue STEM careers. Students who aspired to STEM careers reported significantly higher parental involvement than ones who aspired to non-STEM careers (Mau \& Li, 2018). Family influences and parental involvement have been hypothesized to contribute to the STEM gender equity (Wang \& Degol, 2013). There is agreement that early influences of parents and teachers impact student achievement and career selection (Crisp et al., 2009; Tai et al., 2006; Tyler-Wood et al., 2018).

\section{Learning Experience}

According to Lent et al. (1994, 2000), learning experience refers to a particular life experience that influences career related interests and choice behaviors. Personal career expectations and performance standards, formed through learning experiences, may interact with other realities (e.g., family, school) to influence a career choice (Lent et al., 1994). Studies have shown that students who have positive STEM learning experiences in the early years of their education are more likely to pursue a STEM career (Roberts et al., 2018; Wang, 2012; Wang \& Degol, 2013). Teachers shape students' interests and engagement in STEM education and career development. Teachers can facilitate a social classroom environment by sending positive messages about the nature of student-student relationships (Roberts et al., 2018; Thurlings et al., 2014). Gregory and Weinstein (2004) found greater growth in math achievement for adolescents who felt that their teachers offered praises, listened, and were interested in their students. On the other hand, teachers may hinder student engagement and motivation in STEM education by having gender-based preferences and stereotypes (Mau \& Li, 2018; UNESCO, 2017). In a recent study, Mau and Li (2018) found that math/science teachers that gave unfair treatment were initially significant predictors of STEM aspiration. Yet, the importance of these variables diminished once the STEM self-efficacy variable was included in the prediction model.

However, there are multiple overlapping factors influencing students' STEM learning experiences, especially for girls, in complex ways. These factors vary at the individual (e.g., interest; Mau et al., 2016; Wang, 2012), family (e.g., parental involvement; Ing, 2014), school (e.g., teaching strategies, unfair treatment in schools; Broomhead, 2013; Kermani \& Aldermir, 2015), and societal levels (e.g., social and cultural norms, gender stereotypes; McDaniel, 2015). Specifically, the challenges for girls in their STEM career development result from these factors being embedded in both learning and socialization processes, which are being affected by teachers and parents (McDaniel, 2015).

\section{Individualism and Collectivism}

Research suggested that social and cultural structures contribute to gender difference in STEM (Sy et al., 2007; Triandis, 2001). According to Hofstede (1991), "individualism pertains to societies in which the ties between individuals are loose: everyone is expected to look after himself or herself and his or her immediate family" (p. 51). Collectivism, on the other hand, "pertains to societies in which people from birth onwards are integrated into strong, cohesive in-groups, which throughout people's lifetime continue to protect them in exchange for unquestioning loyalty" (p. 51). That is, collectivist cultures emphasize the pursuit of collective interests in a group over individual ones (Triandis, 2001), while individualist cultures are oriented around the self, being independent instead of identifying with a group mentality (Twenge \& Campbell, 2018). For instance, Yoshikawa et al. (2018) point out that collectivism in Japan leads women to feel a strong social responsibility to play their expected role in their family as primary caregiver, which keeps them away from their career goals. The cultural norm makes it hard for individuals in a collectivist society to change these pervasive gender-based expectations (Yoshikawa et al., 2018). Similarly, individualism is positively related with work and family 


\section{Gender Difference in STEM Career Aspiration and Social-Cognitive}

Factors in Collectivist and Individualist Cultures

responsibilities (Twenge \& Campbell, 2018). Research has indicated that boys and girls develop gendered perceptions of disciplines early in their education (Ganley et al., 2018) and these perceptions may impact gender differences in career interests and choices, steering them toward careers with less discrimination against their gender (Cheryan et al., 2015).

In this study we selected the United States and Taiwan to represent the two opposite ends of the individualist/collectivist culture spectrum as indicated in the Hofstede (2019) data. Although the gender difference in STEM education and career is a global phenomenon, factors influencing gender equity in STEM participation may be culturally dependent. Therefore, we attempted to examine gender equity in two different socio-cultural contexts (a collectivist culture and an individualist culture) by using two large high school samples from the United States and Taiwan.

\section{The Present Study}

The purpose of this study was to investigate gender differences in STEM learning experience, parental involvement, self-efficacy, and how these processes relate to STEM aspiration of high school students. Although the gender difference in STEM education and career is a global phenomenon, factors influencing STEM participation may be culturally dependent. Therefore, we attempted to examine these differences in two different socio-cultural contexts (a collectivist culture and an individualist culture) by using two large high school samples from the United States and Taiwan. In accordance with SCCT, the following questions were examined for each of the two cultures:

1. Are there gender differences in parental involvement, learning experience, STEM selfefficacy, and STEM aspiration of high school students? If so, are there greater gender differences in the collective culture than in the individualist culture?

2. What is the relative importance of the gender, parental involvement, learning experience, and STEM self-efficacy variables in the prediction of high school students' STEM career aspiration?

We expect that students from a "collectivist" cultural context have greater gender differences in learning experience, parental involvement, and STEM self-efficacy than those from an "individualist" cultural environment. We also expected differential prediction models of STEM aspiration derived from the two different socio-cultural contexts.

\section{Participants}

\section{Taiwanese Participants}

For the Taiwanese sample, we recruited 590 Taiwanese high school students from two high schools, one private and one public high school, located in the central part of Taiwan. The sample consisted of 315 males and 275 females $\left(36110^{\text {th }}\right.$ graders, $18811^{\text {th }}$ graders, $4112^{\text {th }}$ graders; age: $M=$ $16.2 ; S D=0.73$.

\section{American Participants}

For the American sample, we used a comparable subsample of 590 high school students randomly selected from a nationally representative sample of 21,444 U.S. high school students sampled from 944 public and private high schools. The sample consisted of 298 males and 292 females (Age: $M=$ $16.5 ; S D=0.63)$. The data file used in the present study is from the High School Longitudinal Study of 2009-2014 (HSLS:09) provided by the U.S. Department of Education, Institute of Education Science (IES), and National Center for Education Statistics (Ingels et al., 2015). 
Gender Difference in STEM Career Aspiration and Social-Cognitive

Factors in Collectivist and Individualist Cultures

\section{Measures}

Measures of learning experience, parental involvement, and STEM self-efficacy used for the Taiwanese sample were created to parallel the measures used in the HSLS:09. The university ethics board (institutional review board) approved this study before we collected data.

\section{STEM Learning Experience}

We operationalized STEM learning experience as students' perception of teachers' pedagogical approach and how they treat their students in math or science classes. Two subscales were involved in this measure:

1. Positive learning experience (14 items, e.g., teacher values/listens to students' ideas). Cronbach's $a$ estimated for the Taiwanese high school sample was .93 and was .88 for the American high school sample.

2. Negative learning experience ( 4 items, e.g., teacher treats some kids better than others). Cronbach's $a$ estimated for the Taiwanese high school sample was .76 and was .70 for the American high school sample.

\section{Parental Involvement in STEM Activities}

Measured by ten survey questions (e.g., helped teenager with math homework; discussed STEM program or article about math, science, or technology with teenager). Cronbach's $a$ was estimated as .89 for both Taiwanese and American samples.

\section{STEM Self-Efficacy}

For the Taiwanese sample, STEM self-efficacy was measured by eight survey questions (e.g., "I am able to get a good grade in my math class", "I am able to complete my science homework"; Cronbach's $\alpha=.92)$. For the American sample, STEM self-efficacy was measured by eight survey questions related to math and science subjects (e.g., "can do excellent job on math tests", "can master skills in science course"; Cronbach's $\alpha=.90$ ). The STEM self-efficacy scale is a composite variable derived from principal-components factor analysis and standardized to a mean of 0 and a standard deviation of 1 using a 4-point Likert scale (Ingels et al., 2015).

\section{STEM Career Aspiration}

For the Taiwanese sample, STEM aspiration was measured by the survey question "I expect to work in the STEM field" using a 5-point Likert scale. Students' responses indicating "agree" or "strongly agree" were classified as being in the STEM group and "strongly disagree" or "disagree" were classified as being in the Non-STEM group. For the American sample, STEM aspiration was measured by the survey question: "Which occupation do you expect or plan to have when you are 30 years old?". Responses to STEM careers were coded into a dichotomous variable, STEM or non-STEM, based on the taxonomy of the Classification of Instructional Program (CIP) codes provided by Kienzl et al. (2009). More specifically, the following occupational clusters were classified as STEM occupations: computer and mathematical occupations; architecture and engineering occupations; and life, physical, and social science occupations.

\section{Data Analyses}


Gender Difference in STEM Career Aspiration and Social-Cognitive Factors in Collectivist and Individualist Cultures

We conducted ANOVA to examine gender difference in STEM parental involvement, classroom experience, and self-efficacy on the two samples described earlier. We then conducted logistic regression analyses using a stepwise variable selection procedure, to examine the relative importance of gender, parental involvement, classroom experience, and self-efficacy on STEM career aspiration. We used Cohen's $d$ to evaluate the strength of a statistical claim. Cohen's $d$ is determined by calculating the mean difference between two groups, and then dividing the result by the pooled standard deviation (Cohen, 1988). Effect size $<0.2$ is considered small, whereas effect size between .02 and .08 is considered medium.

The evaluation of the logistic regression models involved an examination of the chi square goodness of fit, Beta weights, the Wald chi-square statistic, and associated $p$ values were then examined and interpreted for the significant predictors in the models (Mau \& Bikos, 2000). Because of the complex sampling design of the American sample, statistical analyses were weighted by the first follow-up sample weight to adjust for the over sampling bias (Ingels et al., 2015). To do this, we used the following formula: normalized weight $=$ [sample weight] $\times$ [sample $n /$ population $\mathrm{N}$ (sum of weights)] We also used design effects to adjust standard errors for hypothesis testing.

\section{Results}

We organized the results around the two research questions. Because statistical significance is very sensitive to large sample sizes, effect size estimates were used to aid the interpretation of the results. Table 1 presents descriptive statistics and the bivariate analysis results for all of the independent variables by gender and socio-cultural contexts.

\section{Table 1}

Gender Differences in STEM learning experience and parental involvement of Taiwanese high school Students

\begin{tabular}{|c|c|c|c|c|c|c|c|}
\hline & \multicolumn{2}{|c|}{ Male } & \multicolumn{2}{|c|}{ Female } & \multirow[b]{2}{*}{$F$} & \multirow[b]{2}{*}{$p$} & \multirow[b]{2}{*}{$E Z^{*}$} \\
\hline & $M$ & $S D$ & $M$ & $S D$ & & & \\
\hline Positive Learning Experience & 46.91 & 10.95 & 46.28 & 11.6 & .47 & .490 & .00 \\
\hline Negative Learning Experience & 9.88 & 3.45 & 8.30 & 3.3 & 31.29 & .001 & .46 \\
\hline Parental Involvement & 30.86 & 9.0 & 27.20 & 8.7 & 18.87 & .001 & .42 \\
\hline STEM Self-Efficacy & 20.54 & 5.33 & 16.61 & 5.36 & 79.42 & .001 & .74 \\
\hline
\end{tabular}

* Effect size calculated using Cohen's $d$

Question 1: Are there gender differences in parental involvement, learning experience, STEM selfefficacy, and STEM aspiration of high school students? If so, are there greater gender differences in the collective culture than in the individualist culture?

\section{STEM Career Aspiration}


Gender Difference in STEM Career Aspiration and Social-Cognitive Factors in Collectivist and Individualist Cultures

We conducted chi-square tests to examine gender differences in STEM career aspiration separately for the Taiwanese sample and the American sample. We used Cramer's $V$ as an indicator of effect size. Results showed significantly more Taiwanese male (72\%) than female (28\%) students aspired to work in STEM fields $\left(x^{2}=56.04 ; p=0.000\right)$. There were also significantly more American male $(65 \%)$ than female (35\%) students that aspired to work in STEM fields $\left(x^{2}=6.56 ; p=0.007\right)$. We observed a greater effect size in the Taiwanese sample (Cramer's $V=.38$ ) than the American sample (Cramer's $V=$ $.11)$.

\section{Parental Involvement in STEM Activities}

When comparing gender differences in parental involvement, results of ANOVAs showed male Taiwanese students reported significantly greater parental involvement in STEM related activities than female counterparts $(p<.001)$. There were no gender differences in parental involvement in STEM related activities among American high school students $(p<.81)$. As can be seen in the tables, a medium effect size of gender difference in parental involvement was observed for the Taiwanese sample ( $E Z$ $=.42)$, whereas a much smaller effect size was found for American sample $(E Z=.10)$.

\section{Learning Experience}

Results of ANOVA showed male Taiwanese students reported significantly greater negative learning experience in math or science classes than their female counterparts $(p<.001)$. In contrast, female American students reported significantly greater negative learning experience in math or science classes than their male counterparts $(p<.031)$. When we considered the effect size in the interpretation of the results, we found that there was a greater gender difference in learning experience of Taiwanese high school students $(E Z=.46)$ than those of American high school students ( $E Z=.18)$.

\section{STEM Self-Efficacy}

Findings of ANOVA revealed that male Taiwanese students reported significantly higher STEM self-efficacy than female students $(p<.001)$. Similarly, male American students reported significantly higher STEM self-efficacy than their female counterparts $(p<.01)$. However, the effect size statistics suggested that the gender difference in STEM self-efficacy was greater in the collective culture $(E Z=.74)$ than the individualist culture $(E Z=.21)$.

\section{Table 2}

Gender Differences in STEM learning experience and parental involvement of American high school Students

\begin{tabular}{|c|c|c|c|c|c|c|c|}
\hline & \multicolumn{2}{|c|}{ Male } & \multicolumn{2}{|c|}{ Female } & \multirow[b]{2}{*}{$F$} & \multirow[b]{2}{*}{$p$} & \multirow[b]{2}{*}{$E Z$} \\
\hline & $M^{*}$ & $S D$ & $M$ & $S D$ & & & \\
\hline Positive Learning Experience & 26.68 & 5.48 & 26.94 & 5.74 & 134.34 & .20 & .05 \\
\hline Negative Learning Experience & 12.26 & 1.98 & 12.55 & 2.03 & 726.87 & .03 & .18 \\
\hline Parental Involvement & 4.65 & 3.23 & 4.31 & 3.48 & 193.94 & .81 & .10 \\
\hline STEM Efficacy & .84 & .98 & .66 & .90 & 198.03 & .01 & .21 \\
\hline
\end{tabular}

*Weighted sample mean 
Gender Difference in STEM Career Aspiration and Social-Cognitive

Factors in Collectivist and Individualist Cultures

Research Question 2: What is the relative importance of the gender, parental involvement, learning experience, and STEM self-efficacy variables in the prediction of high school students' STEM career aspiration?

\section{Prediction Model}

We conducted logistic regression analyses for both the Taiwanese sample and the American sample to examine the relative importance of the variables predicting STEM career aspirations. See Table 3 for results. For the Taiwanese sample, male students $(b=.85 ; p<.001)$, parental involvement $(b$ $=.04 ; p<.001)$, positive math/science learning experience $(b=.02 ; p<.05)$, perceived negative learning experience in math/science classes $(b=.08 ; p<.01)$, and STEM self-efficacy $(b=.22 ; p<.001)$ significantly predicted STEM aspiration. For the American sample, male students $(b=.53 ; p<.01)$ and STEM self-efficacy $(b=.25 ; p<.05)$ significantly predicted STEM aspiration.

The percentage of variance accounted for by the prediction model for Taiwanese students was $44 \%$. The greater the regression weight, the more the predictor was weighted in the model. As shown in table 3, male students and STEM self-efficacy surfaced as the most important predictors in the model. In comparison, the percentage of variance accounted for by the prediction model of American students was only $11 \%$. Regardless, as with the Taiwanese sample, being a male student and having high STEM self-efficacy surfaced as important predictors for the American sample.

Table 3

Logistic Regression Models Predicting STEM Aspiration: Parameter Estimates and Model Evaluation

\begin{tabular}{lcc}
\hline & $\begin{array}{c}\text { Taiwanese Sample } \\
\text { Beta Weigh }\end{array}$ & $\begin{array}{c}\text { American Sample } \\
\text { Beta Weight }\end{array}$ \\
\hline Gender (M) & $.85^{* * *}$ & $.53^{*}$ \\
Positive Learning Experience & $.02^{*}$ & -.03 \\
Negative Learning Experience & $.08^{* *}$ & .09 \\
Parental involvement & $.04^{* *}$ & -.02 \\
STEM Self-Efficacy & $.22^{* * *}$ & $.25^{*}$ \\
Model evaluation & & \\
Chi-square & $273.27^{* * *}$ & $10.66^{*}$ \\
$\%$ Correct Classification (PCP) & $78.3 \%$ & $60.9 \%$ \\
$\mathrm{R}^{2}$ & .44 & .11 \\
\hline
\end{tabular}

${ }^{*} p<.05 .{ }^{* *} p<.01 .{ }^{* * *} p<.001$.

\section{Discussion}

The present study examined gender differences in STEM aspiration, and social-cognitive factors such as STEM learning experience, parental support, and self-efficacy through samples from collectivist and individualist cultures. We expected that students from a "collectivist" cultural context have greater gender differences in STEM aspiration and social-cognitive factors than those from an "individualist" cultural environment. We also expected a differential prediction of STEM career aspiration as a function 
Gender Difference in STEM Career Aspiration and Social-Cognitive Factors in Collectivist and Individualist Cultures

of STEM learning experience, parental involvement, and STEM math/science self-efficacy between the two cultural groups.

As expected, findings from this study suggested that there were gender differences in STEM aspiration and social-cognitive factors among both the Taiwanese sample and American sample. Findings from this study added to the growing body of empirical literature on gender difference regarding parental involvement, learning experience, and self-efficacy, and STEM career aspiration. In accordance with previous research (He \& Zhou, 2018; Ing, 2014; Mau et al., 2019; Mau \& Li, 2018; Wang \& Degol, 2013), the present study provides additional evidence that gender differences in STEM career interests remain pervasive among high school students. Male students were more likely to participate in the STEM workforce than female students regardless of the socio-cultural contexts. Moreover, our study extended previous research to indicate that this disparity was much more pronounced among students from a "collectivist" cultural context. With the collectivist culture being more group oriented, Taiwanese parents' vocational gender stereotypes are more likely to influence the career choice of their children. Unlike American students, who tend to make their own career decisions, Taiwanese students tend to make career decisions that conform to familial and societal expectations (Mau, 2000).

Examining social-cognitive factors, we found significant gender differences in STEM self-efficacy in both Taiwanese and American students. Our results support prior findings indicating that male high school students reported greater STEM self-efficacy than female students (Brown et al., 2016; Mau \& Bikos, 2000; Mau \& Li, 2018). Similar to Mau and Li (2018), who found that being male, having great parental expectations, and having high math interest and math/science self-efficacy predicted STEM career aspirations, we found that being male and having high STEM self-efficacy predicted STEM career aspirations in both individualist and collectivist contexts. Moreover, our study showed that there was a greater gender difference in STEM self-efficacy within the Taiwanese sample than the American sample. This finding suggested the salient role of social-cultural context in explaining gender differences in STEM self-efficacy.

The present study also showed that Taiwanese male students reported more parental involvement than Taiwanese female students. There was no significant gender difference in parental involvement found for American students. Our study extended previous studies by Leong (1993) and Mau (1997) in showing that the level of parental involvement is not only gender specific but also culturally specific. In particular, results from this study indicated that parental involvement affected Taiwanese high school students' career decision-making significantly more than their American counterparts, and that this disparity was mainly due to their cultural orientation. The collectivist culture emphasizes conformity and collective interests (Yoshikawa et al., 2018), whereas the individualist culture is more focused on the self and being independent rather than group influence, which is why parental involvement is not as significant towards their child's career choices.

The current study also found gender differences in STEM learning experience in both Taiwanese and American students. Interestingly, the present study showed that among Taiwanese students, males reported more differential treatment in math/science classes, whereas among American students, females reported more differential treatment in similar classes. The finding of American female students' perception is consistent with previous research (Mau \& Li, 2018), however, the finding of Taiwanese male students' perception of negative learning experiences deserves more research attention. To our knowledge, there is no study that examined Taiwanese high school students' classroom experience in relation to math/science teachers' preferential treatment. Given that gender difference was not significant for American students due to the much smaller effect size, further investigations are needed to clarify this disparity. 
Gender Difference in STEM Career Aspiration and Social-Cognitive Factors in Collectivist and Individualist Cultures

In examining the relative importance of the variables predicting STEM career aspiration, our study partially confirmed that there were different prediction models for the American and Taiwanese samples. Using SCCT as a conceptual framework, we found that gender, self-efficacy belief, learning experience, and parental involvement all significantly predicted STEM career aspiration of Taiwanese students. To a lesser degree, we also found gender and STEM self-efficacy predicted STEM career aspiration of American students. We did not find that learning experience and parental involvement fit the model well for the American sample. The lack of prediction power of these two variables for American students suggests that the effects of these two variables are culturally specific, which partially confirmed our expectation. Our findings are in line with Mau and Li's study (2018) in that the importance of these variables diminished once math/science self-efficacy were added into the prediction model.

In summary, our results suggest that parental involvement, learning experience, and STEM selfefficacy have greater predictive impact on boys than on girls in a collectivist culture. This finding is consistent with some of the assumptions in gender literature (Ing, 2014; Kanny et al., 2014). Furthermore, the results from both samples indicated that gender and STEM self-efficacy were the two most salient variables in our prediction models, which were in accordance with previous studies (Mau et al., 1995; Twenge \& Campbell, 2018; Wang, 2012). The current findings are generally consistent with other studies focused on gender difference within culturally and ethnically diverse samples (He \& Zhou, 2018; Kermani \& Aldemir, 2015).

\section{Implications for Practice}

The findings of this study, although not widely generalizable, do encourage career and professional school counselors to employ culturally specific classroom guidance programs focused on STEM career aspiration, such as parent training activities that foster parental awareness about the importance of supporting their high schoolers' career development (Ginevra et al., 2015) and enhancing the students' career and college readiness self-efficacy (Martinez et al., 2017). Such guidance programs might provide a unique platform for those students from either a collectivist or individualist cultural background to address career concerns in their immediate social context. More importantly, for female or minority students, career decision-making is not just one's autonomy to choose based on gender or on a prejudicial statement regarding ability and appearance, but rather involved with individual, contextual, and personal cognitive factors (Lent et al., 1994). Addressing these factors in guidance lessons or career counseling groups would provide culturally sensitive career services (e.g., focusing on gender stereotypes and self-efficacy) to this population. Career and professional school counselors will also benefit from learning about female and minority students' career cognitions and attitudes, and increase their multicultural counseling skills and awareness.

\section{Limitations and Future Research}

Our results must be considered in light of several limitations regarding the data and generalizability of the findings. First, our findings were generated from two different data sources, instead of an experimental design. This limited our ability to make direct comparisons between the two cultural groups. Second, our data obtained from the Taiwanese sample were not derived from a nationally representative sample. Generalizability of the findings from the Taiwanese sample is limited to the characteristics of the high school student population from the central part of Taiwan. Third, although the American sample was derived from a nationally representative sample, the data were limited in terms of institutional data files. As such, our models excluded several key variables that have 


\section{Gender Difference in STEM Career Aspiration and Social-Cognitive Factors in Collectivist and Individualist Cultures}

been found in other STEM literature. Lastly, our study focused on gender difference in only two different specific cultural contexts. It was not our intention to provide a comprehensive prediction model of STEM career aspiration. Future research could extend this study to include other relevant variables identified from STEM literature and previous empirical studies.

\section{Conclusion}

The gender inequity in STEM participation and achievement has been a concern for decades. Researchers have suggested that girls and women may not have opportunities to enter the STEM field (Ganley et al., 2018; UNESCO, 2017). The current study extends previous research to show that gender inequity is a function of social-cognitive factors and self-efficacy is one of the most important factors predicting STEM career aspiration of high school students regardless of nationality. In addition, our study suggests that, though gender inequity is a global phenomenon, students from a developing country in a "collectivist" cultural context have greater gender differences in learning experience, parental involvement, and STEM self-efficacy than those from a developed country in an "individualist" cultural environment.

\section{References}

Bandura, A. (1977). Self-efficacy: Toward a unifying theory of behavioral change. Psychological Review, 84, 191-215. https://www.doi.org/10.1037/0033-295x.84.2.191

Broomhead, K. E. (2013). Preferential treatment or unwanted in mainstream schools? The perceptions of parents and teachers with regards to pupils with special educational needs and challenging behaviour. Support for Learning, 28, 4-10. https://www.doi.org/10.1111/1467-9604.12009

Brotman, J. S. \& Moore, F. M. (2008). Girls and science: A review of four themes in science education literature. Journal of Research in Science Teaching, 45, 971-1002. https://doi.org/10.1002/tea.20241

Brown, P. L., Concannon, J. P., Marx, D., Donaldson, C. W., \& Black, A. (2016). An examination of middle school students' STEM self-efficacy with relation to interest and perceptions of STEM. Journal of STEM Education: Innovations and Research, 17(3), 27-38.

Cheryan, S., Master, A., \& Meltzoff, A. N. (2015). Cultural stereotypes as gatekeepers: Increasing girls' interest in computer science and engineering by diversifying stereotypes. Frontiers in Psychology, 6, 1-8. https://www.doi.org/10.3389/fpsyg.2015.00049

Cohen, J. (1988). Statistical power analysis for the behavioral sciences (2nd ed.). Lawrence Earlbaum Associates.

Crisp, G., Nora, A., \& Taggart, A. (2009). Student characteristics, pre-college, college, and environmental factors as predictors of majoring in and earning a STEM degree: An analysis of students 
Gender Difference in STEM Career Aspiration and Social-Cognitive

attending a Hispanic serving institution. American Educational Research Journal, 46, 924-942. https://www.doi.org/10.3102/0002831209349460

Fouad, N. A., \& Smith, P. L. (1996). A test of a social cognitive model for middle school students: Math and science. Journal of Counseling Psychology, 43, 338-346. https://www.doi.org/10.1037/0022-0167.43.3.338

Ganley, C. M., George, C. E., Cimpian, J. R., \& Makowski, M. B. (2018). Gender equity in college majors: Looking beyond the STEM/Non-STEM dichotomy for answers regarding Female participation. American Educational Research Journal, 55, 453-487. https://www.doi.org/10.3102/0002831217740221

Ginevra, M. C., Nota, L., \& Ferrari, L. (2015). Parental support in adolescents' career development: Parents' and children's perceptions. Career Development Quarterly, 63, 2-15. https://www.doi.org/10.1002/j.2161-0045.2015.00091.x

Gregory, A., \& Weinstein, R. S. (2004). Connection and regulation at home and in school: Predicting growth in achievement for adolescents. Journal of Adolescent Research, 19, 405-427. https://www.doi.org/10.1177/0743558403258859

He, G., \& Zhou, M. (2018). Gender difference in early occupational attainment: The roles of study field, gender norms, and gender attitudes. Chinese Sociological Review, 50, 339-366. https://www.doi.org/10.1080/21620555.2018.1430509

Hofstede, G. (2019). Country comparison tool. Retrieved from https://www.hofstede-insights.com. Hofstede, G. (1991). Cultures and organizations: Software of the mind. London: McGraw-Hill. Ing, M. (2014). Gender differences in the influence of early perceived parental support on student mathematics and science achievement and stem career attainment. International Journal of Science \& Mathematics Education, 12, 1221-1239. https://www.doi.org/10.1007/s10763-013$\underline{9447-3}$

Ingels, S. J., Pratt, D. J., Herget, D., Bryan, M., Fritch, L. B., Ottem, R., Rogers, J. E., \& Wilson, D. (2015). High School Longitudinal Study of 2009 (HSLS:09). 2013 Update and High School Transcript Data File Documentation (NCES 2015-036). National Center for Education Statistics, Institute of Education Sciences, U.S. Department of Education. Washington, DC. Retrieved from https://nces.ed.gov/pubsearch/pubsinfo.asp?pubid=2015036 
Gender Difference in STEM Career Aspiration and Social-Cognitive

Jeynes, W. H. (2003). A meta-analysis the effects of parental involvement on minority children's academic achievement. Education and Urban Society, 35, 202-218. https://www.doi.org/10.1177/0013124502239392

Kanny, M. A., Sax, L. J., \& Riggers-Pieh, T. A. (2014). Investigating forty years of STEM research: How explanations for the gender gap have evolved over time. Journal of Women and Minorities in Science and Engineering, 20, 127-148. https://www.doi.org/10.1615/JWomenMinorScienEng.2014007246

Kermani, H., \& Aldemir, J. (2015). Preparing children for success: Integrating science, math, and technology in early childhood classroom. Journal Early Child Development and Care, 185, 15041527. https://www.doi.org/10.1080/03004430.2015.1007371

Kienzl, G. S., George-Jackson, C. E., \& Trent, W.T. (2009). Underrepresented students entering STEM fields. American Educational Research Association. April 13-17, 2009. San Diego, CA.

Lent, R. W., Brown, S. D., \& Hackett, G. (1994). Toward a unifying social cognitive theory of career and academic interest, choice, and performance. Journal of Vocational Behavior, 45, 79-122. https://www.doi.org/10.1006/jvbe.1994.1027

Lent, R. W., Brown, S. D., \& Hackett, G. (2000). Contextual supports and barriers to career choice: A social cognitive analysis. Journal of Counseling Psychology, 47, 36-49. https://doi.org/10.1037/0022-0167.47.1.36

Leong, F. T. L. (1993). The career counseling process with racial-ethnic minorities: The case of Asian Americans. Career Development Quarterly, 42, 26-40. https://www.doi.org/10.1002/j.2161-0045.1993.tb00242.x

Li, J., Mau, W. C., Chen, S. J., Lin, T, C., \& Lin, T. Y. (2019). A qualitative exploration of STEM career development of high school students in Taiwan. Journal of Career Development. https://www.doi.org/10.1177/0894845319830525

Martinez, R. R., Baker, S. B., \& Young, T. (2017). Promoting career and college readiness, aspirations, and self-efficacy: Curriculum field test. Career Development Quarterly, 65, 173-188. https://www.doi.org/10.1002/cdq.12090

Mau, W.C. (2000). Cultural differences in career decision-making styles and self-efficacy. Journal of Vocational Behavior, 53, 365-378. https://doi.org/10.1006/jvbe.1999.1745 
Gender Difference in STEM Career Aspiration and Social-Cognitive

Mau, W. C. (1997). Parental influences on high school students' academic achievement: A comparison of Asian-immigrant, Asian-Americans, and White-American. Psychology in the Schools, 34, 267-277. https://www.doi.org/10.1002/(SICI)1520-6807(199707)34:3<267::AID-PITS9>3.0.CO;2-L

Mau, W. C. (2003). Factors influencing persistence in science and engineering career aspirations Career Development Quarterly, 51, 234-243. https://www.doi.org/10.1002/j.2161-0045.2003.tb00604.x

Mau, W. C., \& Bikos, L. H. (2000). Educational and vocational aspirations of minority and female students: A longitudinal study. Journal of Counseling \& Development, 78, 186-194. https://www.doi.org/10.1002/j.1556-6676.2000.tb02577.x

Mau, W. C., Chen, S. J., \& Lin, C. C. (2019). Assessing high school student's STEM career interests using a social cognitive framework. Education Sciences, 9, 151-162. https://www.doi.org/10.3390/educsci9020151

Mau, W. C., Domnick, M., \& Ellsworth, R. D. (1995). Characteristics of female students who aspire to science and engineering or homemaking careers. Career Development Quarterly. 43, 323-337. https://www.doi.org/10.1002/j.2161-0045.1995.tb00437

Mau, W. C., \& Li, J., (2018). Factors influencing aspirations in STEM careers of underrepresented high school students: A two-year follow-up. Career Development Quarterly,110, 65-84. https://www.doi.org/10.1002/cdq.12146

Mau, W.C., Perkins, V., \& Mau, Y. H. (2016). Gender and racial differences in career decision-making dispositions of college students enrolled in STEM majors. Universal Journal of Psychology, 4 , 254-260. https://www.doi.org/10.13189/uip.2016.040602

McDaniel, A. (2015). The role of cultural contexts in explaining cross-national gender gaps in STEM expectations. European Sociological Review, 32, 122-133. https://doi.org/10.1093/esr/jcv078

Raque-Bogdan, T. L., \& Lucas, M. S. (2016). Career aspirations and the first-generation student: Unraveling the layers with social cognitive career theory. Journal of College Student Development, 57, 248-262. https://www.doi.org/10.1353/csd.2016.0026

Roberts, T., Jackson, C., Mohr-Schroeder, M. J., Bush, S. B., Maiorca, C., Cavalcanti, M., Schroeder, D. C., Delaney, A., Putnam, L., \& Cremeans, C. (2018). Students' perceptions of STEM learning after participating in a summer informal learning experience. International Journal of STEM Education, 5, 1-14. https://www.doi.org/10.1186/s40594-018-0133-4 
Gender Difference in STEM Career Aspiration and Social-Cognitive

Sy, S., Rowley, S., \& Schulenberg, J. (2007). Predictors of parent involvement across contexts in Asian American and European American families. Journal of Comparative Family Studies, 38(1), 1-29. Retrieved from http://www.jstor.org/stable/41604120

Tai, R. H., Qi Liu, C., Maltese, A. V., \& Fan, X. (2006). Career choice. Planning early for careers in science. Science, 312, 1143-1144. https://www.doi.org/10.1126/science.1128690

Thurlings, M., Evers, A. T., \& Vermeulen, M. (2014). Toward a model of explaining teachers' innovative behavior: A literature review. Review of Educational Research, 85, 430-471. https://www.doi.org/10.3102/0034654314557949

Triandis, H. C. (2001). Individualism-collectivism and personality. Journal of Personality, 69, 907-924. https://www.doi.org/10.1111/1467-6494.696169

Twenge, J. M., \& Campbell, K. W. (2018). Cultural individualism is linked to later onset of adult-role responsibilities across time and regions. Journal of Cross-Cultural Psychology, 49, 673-682. https://www.doi.org/10.1177/0022022118764838

Tyler-Wood, T., Johnson, K., \& Cockerham, D. (2018). Factors influencing student stem career choices: Gender differences. Journal of Research in STEM Education, 4(2), 179-192.

United Nations Educational, Scientific and Cultural Organization (UNESCO; 2017). Cracking the code: girls' and women's education in science, technology, engineering and mathematics (STEM). Retrieved from: https://unesdoc.unesco.org/ark:/48223/pf0000253479

Usher, E., Ford, C., Li, C., \& Weidner, B. (2019). Sources of math and science self-efficacy in rural Appalachia: A convergent mixed methods study. Contemporary Educational Psychology, 57, 3253. https://doi.org/10.1016/j.cedpsych.2018.10.003

Wang, M. T., \& Degol, J. L. (2013). Gender gap in science, technology, engineering, and mathematics (STEM): Current knowledge, implications for practice, policy, and future direction. Education Psychology Review, 29(1), 119-140.

Wang, M. T. (2012). Educational and career interests in math: A longitudinal examination of the links between classroom environment, motivational beliefs, and interests. Developmental Psychology, 48, 1643-1657. https://www.doi.org/10.1037/a0027247

Yoshikawa, K., Kokubo, A., \& Wu, C. H. (2018). A cultural perspective on gender inequity in STEM: The Japanese context. Industrial \& Organizational Psychology, 11, 301-309. https://www.doi.org/10.1017/iop.2018.19 


\section{About the Authors}

Wei-Cheng J. Mau, Ph.D. (joseph.mau@wichita.edu) is a professor at the Department of Counseling, Educational Leadership, Educational and School Psychology, Wichita State University. His research focuses on educational and vocational aspirations, STEM interests, career decision-making, and career development of underrepresented students.

Shr-Jya Chen, Ph.D. (sjc@thu.edu.tw) is an associate professor at the Graduate Institute of Education, Tunghai University in Taiwan. Her research interests include educational administration and leadership, teacher education and secondary education.

Jiaqi (Jason) Li, Ph.D., LPC, NCC. (Jason.li@wichita.edu) is an associate professor in the Department of Counseling, Educational Leadership, Educational and School Psychology in the College of Applied Studies at Wichita State University. He received his PhD in Counselor Education and Supervision at Texas Tech University. His research interests were broadly in the areas of career development, addictive behaviors, and mental issues of underrepresented groups in the school setting. He is a licensed professional counselor and national certified counselor in the state of Kansas.

Emily Johnson (ecjohnson4@shockers.wichita.edu) is a graduate student in the higher education counseling program at Wichita State University. Her research interests include the effects of career counseling and the mental health of college students. 